\title{
Microwave Metallurgy: Synthesis of Intermetallic Compounds via Microwave Irradiation
}

Jonathan W. Lekse, Tristan J. Stagger and Jennifer A. Aitken*

\section{Supplementary Information}

Description:

Page \#

Additional Experimental Details: $\mathrm{Ag}_{3} \mathrm{In}$

S2

Additional Experimental Details: $\mathrm{Bi}_{2} \mathrm{Pd}$

S3

Details for Additional Intermetallic Compounds

S4

PXRD AuIn 2 Sample Size Comparison

S5

PXRD analysis of $\mathrm{a} \mathrm{Bi}_{3} \mathrm{Ni}$ sample

S6

PXRD analysis of a $\mathrm{Bi}_{3} \mathrm{In}_{5}$ sample

S7

PXRD analysis of a $\mathrm{Cu}_{11} \mathrm{In}_{9}$ sample 
Silver metal powder 325 mesh $99.99 \%$ was used as purchased from Cerac. Indium metal powder $99.99 \%$ was used as purchased from Strem. Varying amounts, typically 1 mmole, of a stoichiometric mixture of silver and indium were weighed out and placed into a $9 \mathrm{~mm}$ fused-silica tube. $\mathrm{Ag}_{3} \mathrm{In}$ was prepared by combining $0.3236 \mathrm{~g}$ of silver powder and $0.1148 \mathrm{~g}$ of indium. Samples were not ground because the both metals are soft and smear instead of grinding. The tube was then sealed under a vacuum of $10^{-3}$ torr and shaken to mix the silver and indium. The sealed tube was placed into a vertical sample holder in a CEM MDS 2100 microwave and irradiated for approximately 1 to 3 minutes at $100 \%$ power. Following irradiation the tube was opened and the sample collected, ground and analyzed. 
Bismuth metal powder 200 mesh $99.999 \%$ was used as purchasedfrom Cerac. Palladium metal powder $\sim 60$ mesh $99.95 \%$ was used as purchased from Strem. Stoichiometric amounts of the elemental starting materials to make 1 mmol of product $(0.4180 \mathrm{~g} \mathrm{Bi}$ and $0.1064 \mathrm{~g} \mathrm{Pd}$ ) were weighed out and placed into a $9 \mathrm{~mm}$ fused-silica tube. Samples were not ground because the both metals are soft and smear instead of grinding. The tube was then sealed under a vacuum of $10^{-3}$ torr and shaken to mix the bismuth and palladium. The sealed tube was placed into a vertical sample holder in a CEM MDS 2100 microwave that was set to irradiate for 10 minutes at $100 \%$ power. Reactions typically had to be stopped after approximately 4 minutes to prevent implosion of the tube. Following irradiation the tube was opened and the sample collected, ground and analyzed. 
Silver metal powder 325 mesh 99.99\%, gold metal powder 325 mesh $99.95 \%$ and bismuth metal powder 200 mesh 99.999\% were used as purchased from Cerac. Indium metal powder $99.99 \%$, copper metal 100 mesh $99.999 \%$ and palladium metal powder $\sim 60$ mesh 99.95\% were used as purchased from Strem. Nickel metal powder 325 mesh 99\% was used as purchased from Sargent-Welch. Stoichiometric amounts of the elemental starting materials, typically to make $1 \mathrm{mmol}$ of product, were weighed out and placed into a $9 \mathrm{~mm}$ fused-silica tube. Samples were not ground because the both metals are soft and smear instead of grinding. The tube was then sealed under a vacuum of $10^{-3}$ torr and shaken to mix the starting materials. The sealed tube was placed into a vertical sample holder in a CEM MDS 2100 microwave and irradiated for 1, ten-minute interval at $100 \%$ power. Following irradiation the tube was opened and the sample collected, ground and analyzed. 


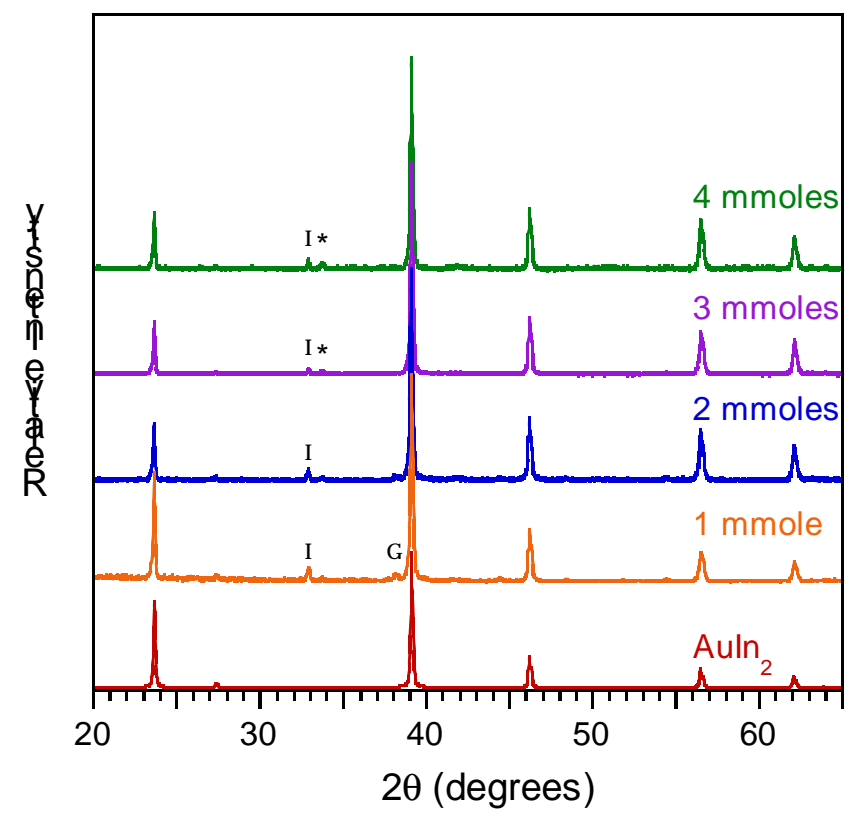

Fig. S1 Comparison of normalized powder X-ray diffraction (PXRD) patterns for 1, 2, 3 and $4 \mathrm{mmol}$ samples that were irradiated in a microwave for 1, ten-minute interval. The majority of the diffraction peaks can be indexed to $\mathrm{AuIn}_{2}$. Unwanted diffraction peaks can be attributed to indium (I), gold (G) and one peak (*) that has not been indexed. 


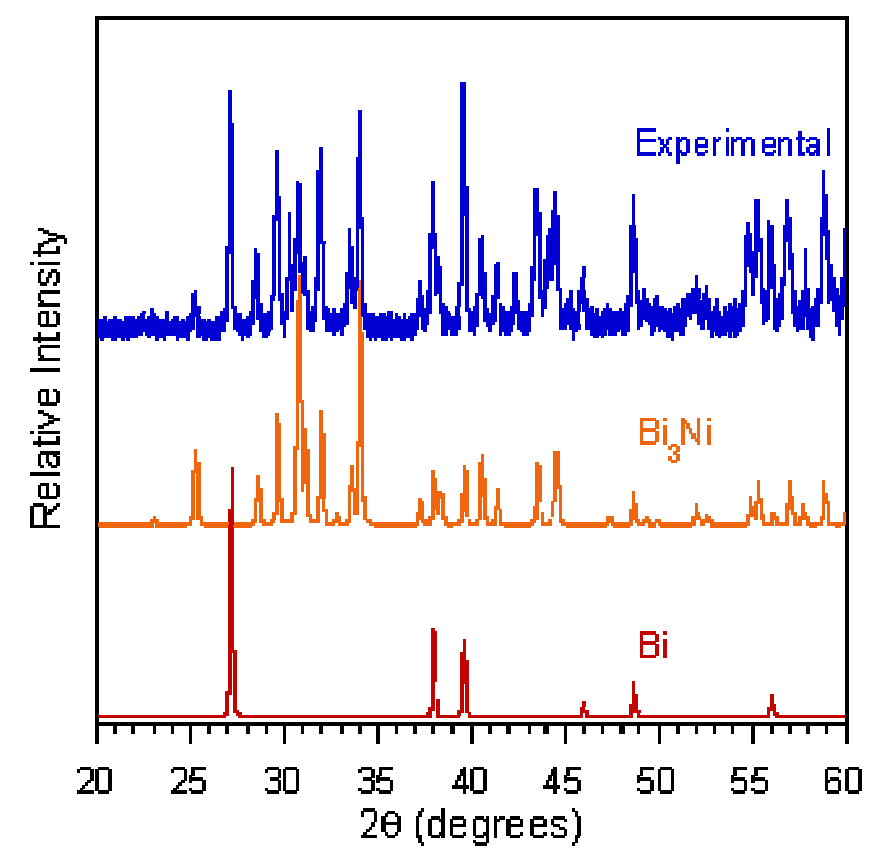

Fig. S2 Comparison of normalized powder X-ray diffraction (PXRD) patterns for the product of the irradiation of a 3:1 mixture of $\mathrm{Bi}$ and $\mathrm{Ni}, \mathrm{Bi}_{3} \mathrm{Ni}$ (JCPDS \# 00-054-0537) and Bi (JCPDS \# 01-071-4642). Though there appears to be unreacted bismuth there is no evidence of unreacted nickel. It is possible that the nickel could be present in an amorphous phase. 


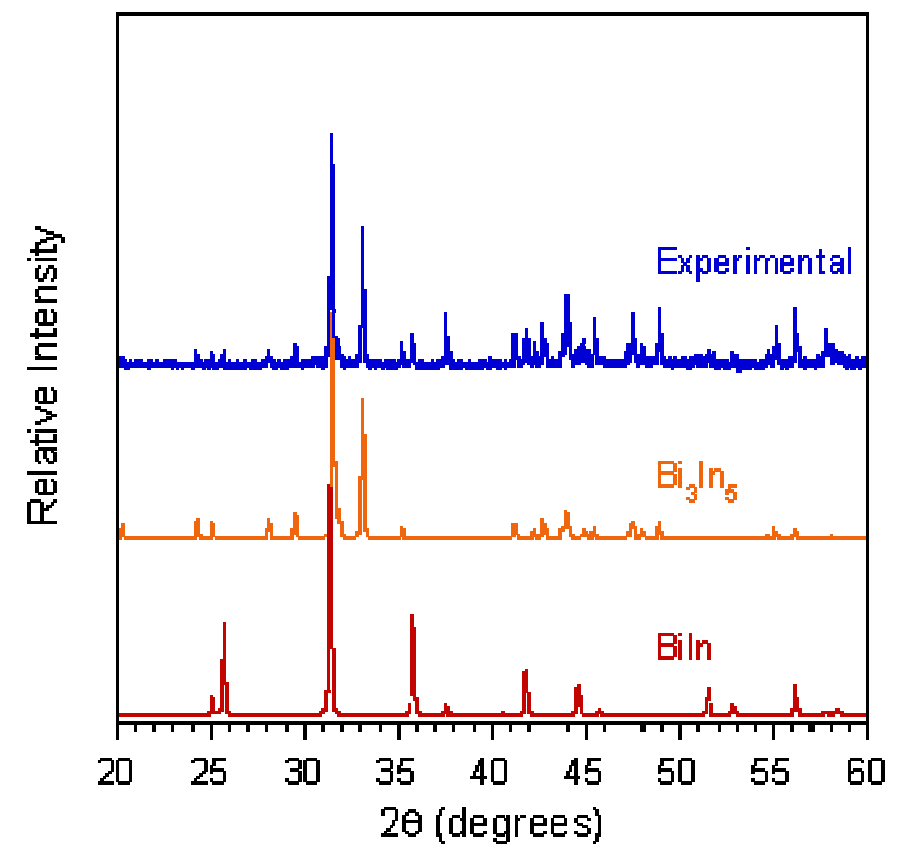

Fig. S3 Comparison of normalized powder X-ray diffraction (PXRD) patterns for the product of the irradiation of a 3:5 mixture of $\mathrm{Bi}$ and $\mathrm{In}, \mathrm{Bi}_{3} \mathrm{In}_{5}$ (JCPDS \# 01-071-0225) and BiIn (JCPDS \# 01-085-0343). The product appears to be primarily $\mathrm{Bi}_{3} \mathrm{In}_{5}$ with a small amount of BiIn. 


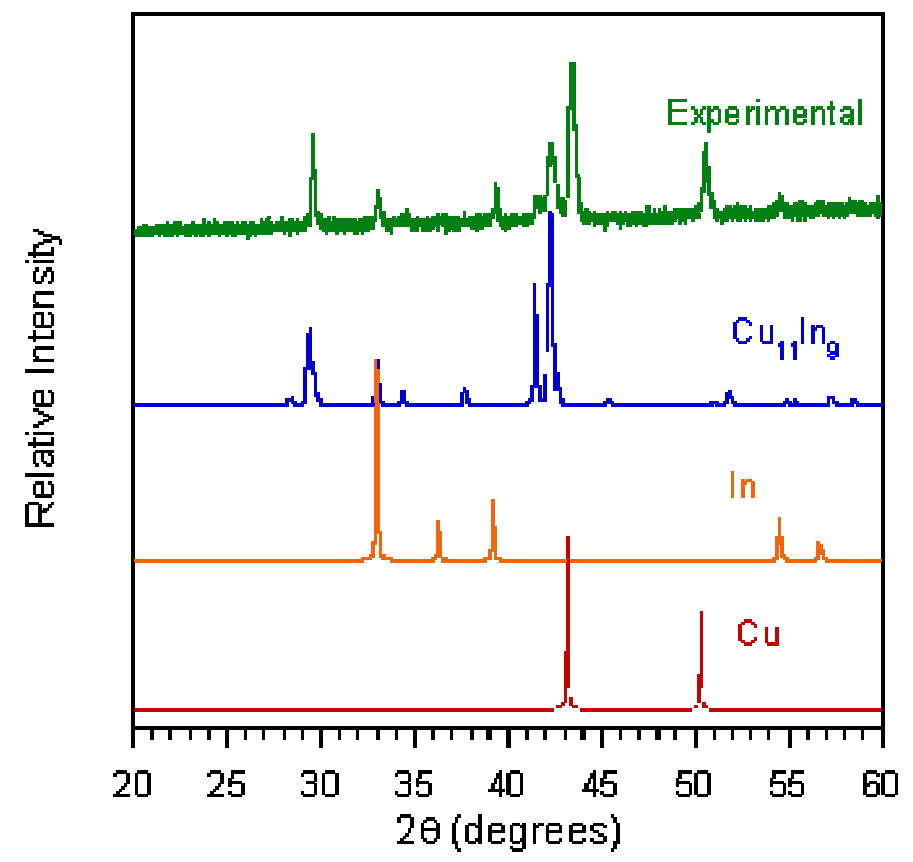

Fig. S4 Comparison of normalized powder X-ray diffraction (PXRD) patterns for the product of the irradiation of a 1:1 mixture of $\mathrm{Cu}$ and $\mathrm{In}, \mathrm{Cu}_{11} \mathrm{In}_{9}$ (JCPDS \# 03-065-4963), $\mathrm{Cu}$ (JCPDS \# 00-004-0836) and In (JCPDS \#00-005-0642). The product appears to be a mixture of $\mathrm{Cu}_{11} \mathrm{In}_{9}$ and unreacted starting material. 